\title{
Running into Trouble: Constructions of danger and risk in girls' access to outdoor space and physical activity
}

Young people's relationship to risk has been premised in a range of recent UK policy and media generated concerns around their general health and wellbeing (Bailey, 2011; DfES, 2003;

Unicef, 2007). Such concerns can be seen to contribute to a larger set of 'youth at risk' discourses, which have been identified as operating in relation to both young people's perceived culpability in the 'obesity epidemic' (Evans, et al., 2008; Gard and Wright, 2005) as well as their physical safety in outdoor spaces (Skelton, 2000; Walkerdine, 1999; Watt and Stenson, 1998). The DfES Every Child Matters (2003, p.6-7) paper for example, identifies well being in terms of both "living a healthy lifestyle" as well as "staying safe" from harm and neglect. Conversely, sport and physical activity is often portrayed as a preventative measure in averting young people's risk to various perceived social problems (Bailey, et al., 2007; Cebulla and Tomaszewski, 2009; Pike, 2007).

As Kelly (2001, p. 23) points out, 'youth-at-risk' discourses can be seen to operate both at the level of manufactured uncertainty as well as within rational "neoliberal projects of government", which serve to regulate young people's activities. Such discourses are inevitably gendered, often calling up women's particular 'vulnerability' in justifying their restriction from perceived risks, including sports. Laurendeau and Adams (2010, p. 437) point out the strongly gendered nature of risk discourses that have systematically "marked women as subjects of risk" thereby constraining women's activities as they are constructed as subjects in need of policing.

This paper traces the operation of risk discourses in and around girls' participation in physical activities in local outdoor spaces. The research findings reveal that despite the appeal of more unstructured outdoor activities for many girls, their physically active pursuits in local areas were commonly framed by concerns around their sexual safety and vulnerability in these settings.

The paper maps out how certain spaces became constructed as either 'safe' or 'unsafe/dangerous' for girls and the impact this had on their participation in physical activities. I thereby highlight some of the discursive contradictions of girls' participation in physical activities and suggest that the disproportionate focus on young women's vulnerability both 
serves to limit their access to physical activity as well as drawing attention away from the girls' own agency in negotiating these physical and discursive landscapes.

\section{Young People and Space}

Recent interest in young people's relationships to 'space' and 'place' have emphasised both the geographic constraints imposed on young people and their creative use of space in contesting and shaping their local environments (Christiansen and O'Brien, 2003; Hall, et al., 1999; Laurie, et al., 1999; McGrellis, 2005; Nespor, 1997). As subjects of risk discourses, young people have been positioned both as vulnerable and at risk to dangers 'out there;' or as comprising threats themselves by occupying public spaces such as the street in ways that are deemed to be unacceptable (Matthews, et al., 2000; Nayak and Kehily, 2008). As Pain (2003:152) argues, this paradox is crucially upheld through "the production and regulation of young people's space." As such it works both to vilify young people as well as imposing restrictions on their activities and mobility (Beunderman, et al., 2007).

Prior work into young people's use of space has drawn attention to the particular salience of class, gender and ethnicity in defining their use of space and in mapping these spaces out as either 'safe' or 'unsafe' (Dwyer, 1998; Johansson et al., 2012 Matthews, et al., 2000; Neary, et al., 2013; Skelton 2000; Watt and Stenson, 1998). While young people have been shown to enact aspects of their ongoing identities within these spaces, much of this work has also pointed out particularly gendered restrictions in documenting girls' limited mobility in comparison with male peers.

Girls' relationships to physical activity and outdoor space can be seen as contradictory since although concerns are often expressed about girls' physical inactivity (Flintoff and Scraton, 2001; UK Sport, 2006; Vilhjalmsson and Kristjansdottir, 2003), so too are concerns raised about their safety in outdoor spaces such as the parks, streets and fields that such activities often require. Young women can be seen to occupy discursive positions both of 'at-risk' girls under threat of sexual violence and aggression (Walkerdine, 1999), as well as neoliberal, responsible subjects expected to manage their personal well-being through health-related body projects (Brumberg, 1997; Evans, et al., 2008). As Harris (2004) argues, such constructions position girls 
within what she terms the 'can do'/'at risk' paradigm where they are rendered both responsible for their health and personal development within a neoliberal framework and also culpable for any failure to overcome structural barriers to these forms of engagement. Young women are often expected to manage such risks in ways that are deemed 'safe', responsible and preventative, for example through organised sport or fitness classes. Within my research girls both resisted discourses of female vulnerability in challenging constraints on being allowed out, as well as subscribing to internalised fears about their safety based in experiences of gendered harassment.

At the transition to secondary school, my observations of the girls' activities also recorded the rising intensity of sexualised taunts, gazes and innuendos around girls' bodies both in mixed PE lessons and outdoor activities where girls' 'bodies-in-motion' were also 'bodies-on-display' (Evans, 2006). The significance of both girls' access to space and the heightened sexualised meanings around their bodies came to take on increasing relevance for girls' participation in physical activity, particularly as their ability to play outside was often restricted on the basis of a perceived sexual threat or danger. In this way, discourses of gender/sexuality (often enforced through harassment) form powerful frameworks whereby both culturally intelligible identities and 'safe/unsafe' spaces can be mapped out. This has specific implications for girls' engagement in physical activities. Yet beyond this narrative of risky/at-risk, girls were also able to test out their sexual agency in particular 'safe' spaces, meanwhile challenging conceptions of their bodies as weak or otherwise vulnerable.

Throughout the paper I seek to explore the connections and interactions between girls' embodied physicalities and their locatedness in both physical and discursive space. Girls' embodied interactions with their gendered physical activity contexts including PE lessons, parks and playing fields are considered to be both dynamic and interactive, representing the potential for shifts in meanings around girls' bodies and the spaces they occupy.

\section{The Research}

The data is drawn from research into girls' participation in sport and physical activity over the transition to secondary school. In this research I looked primarily at girls' participation in 
organised sports settings including their PE lessons, playtime and extracurricular sports clubs. Findings from the research also suggested that girls often enjoyed less structured physical activity settings such as kicking a ball in the park, going for a run nearby or jumping on their trampoline in the back garden. This less formalised activity engagement seemed to provide more freedom for the girls in terms of the relationships it engendered and the relaxed structure of physical activities on offer. The research took place over four years between 2005 and 2008 with girls who initially attended two ${ }^{i}$ state primary schools in London and then followed up with them as they went on to secondary school. Gazza, Danny and Lindsay all attended a diverse comprehensive secondary school in a disadvantaged, inner city area. Nilay, who had attended primary school with these girls, went on to a Muslim girls' school nearby. Nirvana and Lucy attended a middle class, high achieving secondary school on the suburban outskirts of London and Spirit attended a private girls' secondary also nearby. My research interests came to focus on those girls who were particularly active and 'sporty' at primary school and I was able to follow up with these six girls as they continued to their respective secondary schools. Over this period of time I was able to observe PE lessons, extracurricular activities and other out-of-school sports clubs that girls were involved with. The girls were interviewed at least twice in Years 5, 6, 7 \& 8 of their schooling where we talked about their sports involvement, friendships, schoolwork and other interests. I also spoke over the years with parents, teachers, friends and peers about girls' ongoing sports involvement and participation in physical activity.

The research is thus longitudinal in that it spans four years from the time the girls were in Year 5 (10-11 yrs.) until Year 8 (13-14 yrs.). When the girls were in Year $8 \mathrm{I}$ also gave them disposable cameras and asked them to take photos of places where they spent time and liked to be. This request followed on from an emerging topic within the research on the relevance of space (and particularly access to outdoor space) as affecting girls' ability to take part in physical activity and sport. I used the photos during our interviews to elicit stories from the girls about these particular spaces and how they were making use of them. 


\section{Keeping Close to Home: spatial restrictions on girls' activities}

It was clear when the girls were still in primary school that access (or lack of access) to the local area was a significant issue in their ability to engage in outdoor physical activities. This was the case both for girls living in more deprived neighbourhoods in inner city London and those in affluent suburban neighbourhoods that might be considered statistically 'safer.' Parents voiced general concerns about their daughters being outside unsupervised, and therefore girls were either held back from doing outdoor activities or did these under the guardianship of an adult. In consequence, play or other physical activities were contained, supervised or restricted in their scope. Guest (2012: 168) suggests that such "social, physically active pastimes outside of organized contexts" are characteristic of middle childhood and thus constitute important aspects of childhood culture. Sites of leisure and play that the girls could take part in were often close to home, such as this photo Nirvana took of the trampoline in her back garden.

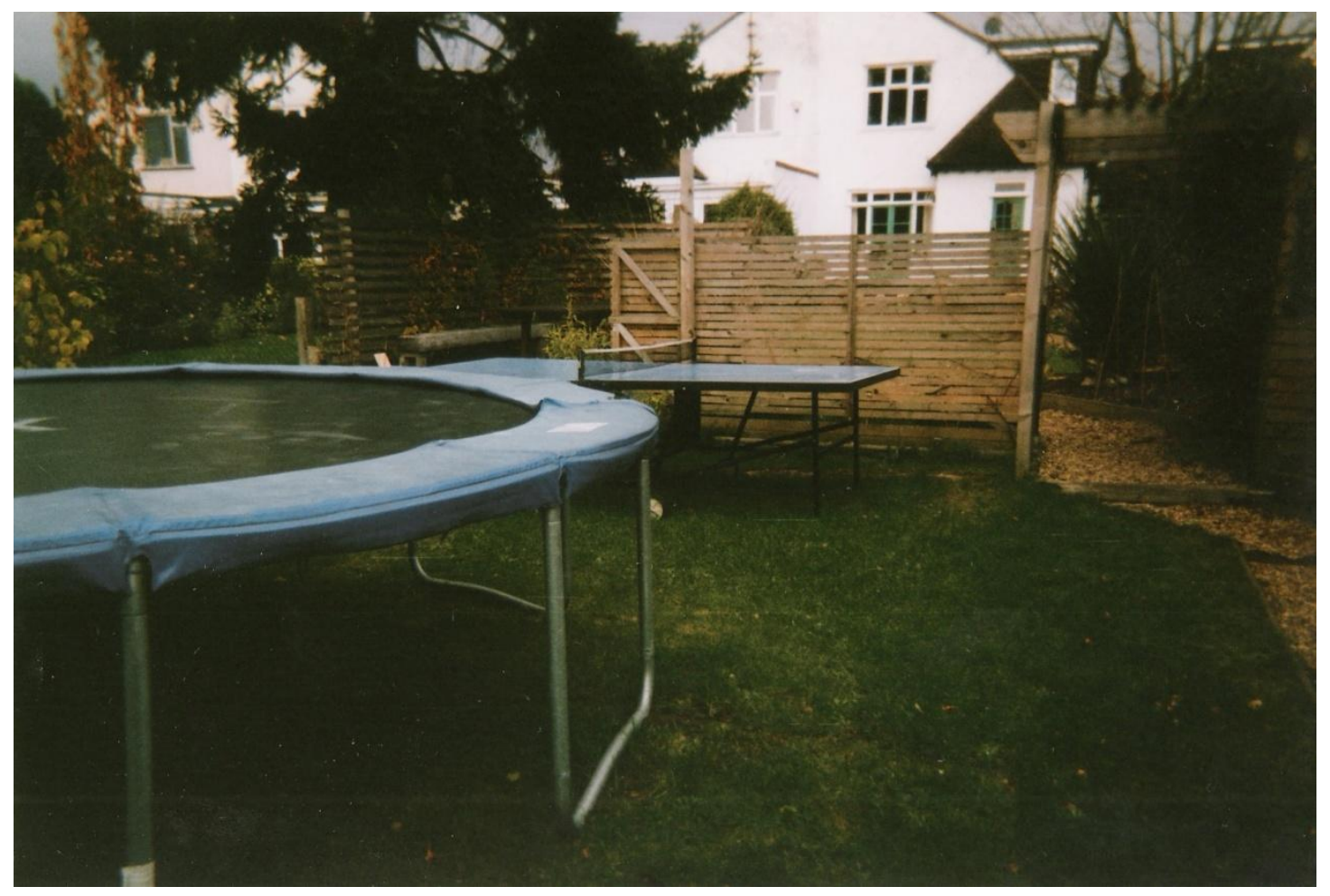

Figure 1. Nirvana's back garden 
Lucy, who had a twin brother and two older brothers, seemed to experience more freedom than her female peers. In our interview, her mother was critical of parental tendencies to limit girls' ability to go outside and explained that this limited Lucy's play options. Lucy found it difficult to find girls her age to accompany her on bike rides and swims at the local pool since her friends were required to have parental supervision.

Gazza's mother was particularly concerned about the safety of their local community space. This is an excerpt from an interview with her mother, Paula, where we discussed Gazza's activities within her neighbourhood. Gazza was in Year 6 at the time.

Paula: But they stay at home, they've never played out.

Sheryl: Really?

Paula: We live on a street so, no.

Sheryl: Are there any parks nearby?

Paula: No. Not safe ones, no.

Paula's conceptualization of their neighbourhood understands this space as being 'not safe' and therefore inappropriate for her daughter to play in. The family lived in a block of flats in central London, nearby to Gazza's school. Since she was not allowed outside on her own Gazza resorted to practicing her football skills in the front corridor by kicking the ball against the wall. During the photo project, Gazza took this picture of the park near her house where she was allowed to play only intermittently under her mother's supervision. 


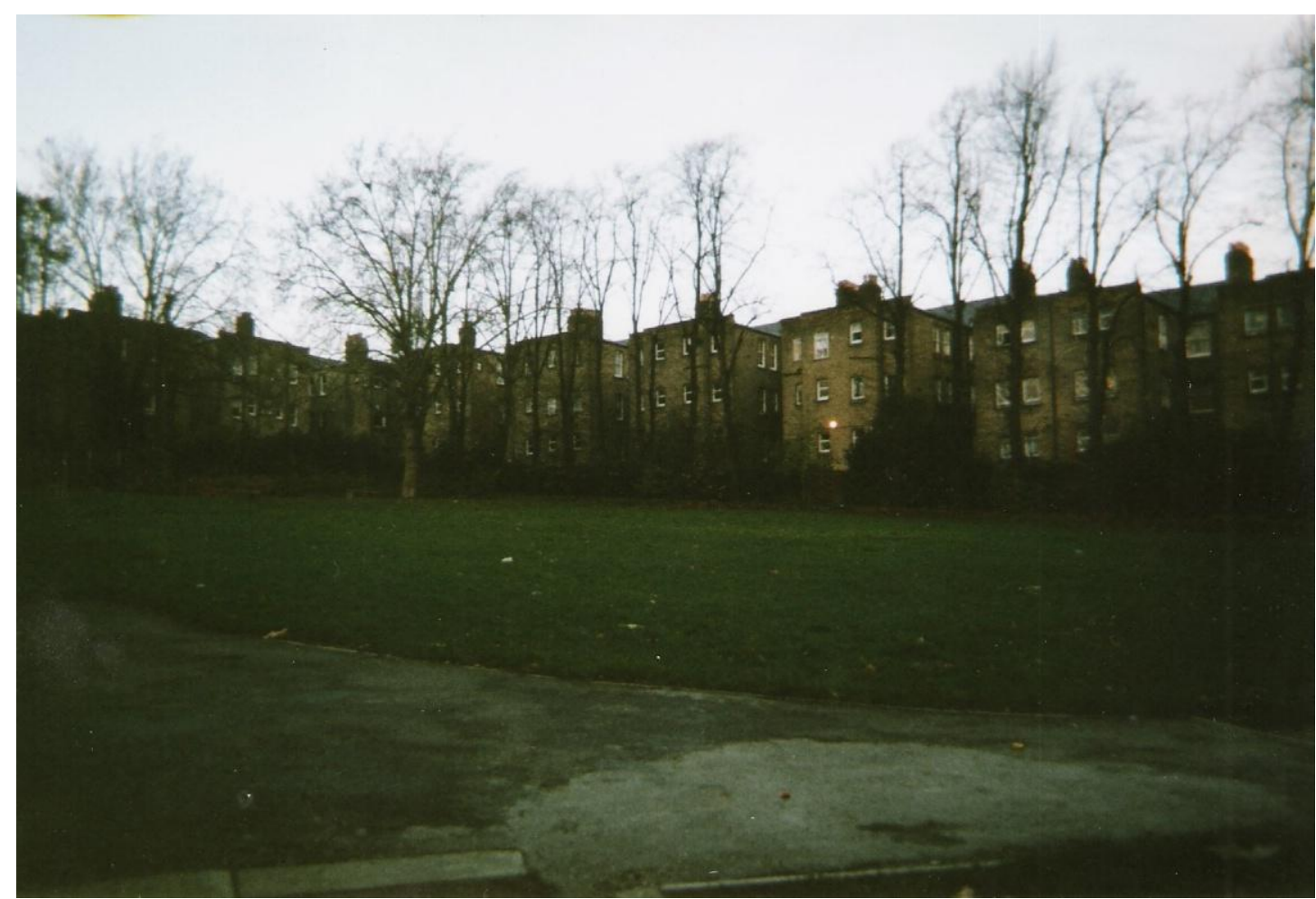

\section{Figure 2. Park near Gazza's home}

The spatial restrictions placed on Gazza's football pursuits were also mirrored at school where the allocated football pitches both dominated the playground space and were controlled by male peers.

Similar to Gazza, Spirit's parents fears for her safety caused her outdoor activities to be highly guarded. She was not permitted to run outside on her own and was accompanied each morning by her father on her daily run. As she entered Year 7, Spirit's increased interest and abilities in running demanded longer distances and more space. Her father could no longer keep up with her on runs and so her parents found a park nearby where they could stand as Spirit ran around the park in circles. Spirit's running was confined to these supervised runs and to the track sessions she took up with a nearby competitive running club. Similarly, these sessions involved Spirit and the other girls running around the track in quick pursuit of one another while their coach critically surveilled their progress by calling out their lap times and commenting on their positioning within the group, shouting 'come on' and 'keep up' to 
individual girls whose speed and stamina he deemed to be lacking (Fieldnotes, Champions Running Club, Summer 2007).

The surveillance and limited spatiality of Spirit's running opportunities contrast with Spirit's own feelings about running, which emphasised freedom, pleasure and a sense of adventure in the exploration of new territory. During our Year 7 interview (when she was twelve) she explained how running made her feel.

Spirit: I just love the feeling of running as well, especially cross-country. Because you don't know where you're going, that's what I love about it. You don't know what anything's going to be-

Despite having to run on the track with her club over the summer training period, Spirit always insisted that it was cross-country running that she preferred, and here she emphasises in particular the exploratory, revelatory nature of this experience. Spirit's description conveys a sense of bodily engagement and physical exhilaration that closely links physiological and psychological experiences in what might be termed a "circuit of body reflexive pleasure" (Wellard, 2012). Within this scheme, the combined contexts of bodily engagement, outdoor space and a sense of discovery combine to create a pleasurable memory/anticipation for Spirit when she tries to recall why she enjoys running. It seems unlikely that the experience she describes here could be easily replicated by running around in circles under the supervision of her parents.

Nespor's (1997) use of children's social 'mapping' similarly revealed girls' more limited spatial territories in their neighbourhoods, compared to those of boys. The impact of spatial restrictions on girls' embodied physical identities has been less explored, although Holman, Johnson and Lucier (2013) found that body-based harassment impacted on girls' willingness to engage in physical activities. The effects of harassment and perceived threats may be particularly relevant to girls or women whose activities demand a wide reign of outdoor space. Wesely and Gaarder (2004) suggest that women's enjoyment of trail running and mountain biking in outdoor space was tempered by security concerns in these spaces. Women's negotiation of the threat of sexual danger through a variety of strategies simultaneously 
compromised their autonomy and led to increased surveillance and reliance on technology (Wesely and Gaarder, 2004). Likewise for girls and young women who pursue outdoor activities such as cycling or distance running, the implications of restricted mobility are particularly relevant and their ability to run freely and 'trouble free' is compromised both by experiences of harassment and by ongoing discourses of sexual threat and vulnerability both inside and outside the school.

\section{Girls as weak and defenceless}

The idea that sexual predators were at large, waiting to target young girls seemed well entrenched both in the suburban middle class enclave and in inner city London. Such fears rested in a characterisation of girls (in particular) as weak and defenceless. Here Danny (a White, working class, Year 7 girl) reports that her teachers also put across similar ideas. As a distance runner who enjoyed running at her local park, this was something she particularly resented. During their PE lesson, the girls expressed their dislike of the PE teacher they had that day.

Danny: I hate this teacher.

Lindsay: He always lectures us for like thirty minutes.

Danny: He's always giving us lectures about how running is good for us, then he says 'don't run alone 'cause strange men are out there watching you.'

(Fieldnotes, Bryckman's School, Summer 2007)

Danny's complaint about her teacher was especially interesting to me since the teacher's direction of the mixed football sessions that day emphasised participation and encouragement above overt competition; an attempt / took to be aimed at combating male domination within the lesson. Danny's critique of her teacher's comments here might therefore be seen as an opposition to the ways in which the justification of girls' participation in sports often simultaneously frames girls as incapable, incompetent and 'at risk.' Danny might be regarded as an exception among her peers in that any fears around sexual threats did not seem to 
impede her participation in either running or football. This may relate to a particular selfconfidence she seemed to possess both in terms of her physical abilities and relationships with other girls.

Like Lucy, Danny also seemed to have very accommodating parents who wanted to encourage her activities and relative freedoms. However, restrictions imposed or advocated by parents and teachers did not always translate into acquiescence for other girls. They often

described occasions in which they had snuck out of the house together and such accounts became noted recurrences in our interviews where they excitedly discussed the details. Spirit and Nirvana recounted an occasion where they had gone carolling with another friend unaccompanied, each girl telling her parents that another parent would be supervising. The commonality and importance of such incidents suggest a kind of 'rite of passage' during which girls tested out the boundaries and limits of the home/public divide.

In our Year 6 interview, Lindsay and Nilay (both Asian Muslimii) described a recent incident in which they had snuck out of the house together and gone to a nearby park. Once there, the girls found that several of their male classmates were, unbeknownst to them, hanging out at the park on a regular basis. Later in the interview they went on to discuss this discrepancy more critically and to reflect on the reasons they were not allowed out on their own.

Lindsay: Well sometimes I feel I should be a boy.

Sheryl: Yeah?

Lindsay: Because sometimes I feel like, sometimes girls don't get the right to do some stuff. Like to hang out. Girls don't really hang out. My mum, like, my brother, she won't worry so much if he comes a bit late because he's a boy and he knows what he's doing. Girls, if we come a bit late she starts going mad.

Sheryl: Really?

Lindsay: 'Cause girls, like girls are girls and big men can do anything to girls because girls are like quiet and they-

Nilay: - they don't really know like nothing to like defend themselves. 
Sheryl: Defend themselves?

Lindsay: Yeah. That's why we'd like being a boy because you get to do whatever you like. Sometimes.

Similar to the other girls, Lindsay and Nilay's access to public spaces was bound by constructs around gender. The girls' venture into their local park had obviously been quite exhilarating for them and they spoke about it in rushed, raised voices that fell over one another. When the girls were 'discovered' by Nilay's mother, her willingness to cover this up (so as not to alert Lindsay's parents), seemed to add to the pleasure of the excursion in the sense that they had 'gotten away with it.' The illicitness and thus excitement of the trip contrast with the mundaneity of their male peers' presence, which is normalised as simply 'where the boys hang out.' This contrast seemed to characterize the very different ways in which boys and girls were treated in relation to outdoor freedoms and perceived safety. The sense of transgression seems to allow the girls to express their resistance towards gendered constructs of space. However this is quickly retracted through the reiteration of normative gendered constructs of feminine vulnerability and masculine aggression.

Despite the girls' joint sense that this discrepancy in personal freedom with their male peers was unfair, the characterisation of girls as 'weak, defenceless and quiet' is used to justify their limited mobility and even to frame it as protective and for their own good. The juxtaposition of 'big men' and 'little girls' discursively positions the girls as both physically small and particularly vulnerable whilst the threatening 'big man' conjures up notions of sexual predators without social consciences or constraints. In contrast, Lindsay's brother (and seemingly other boys as well) are here positioned as 'streetwise,' capable of defending themselves even against 'big men.' In a later interview, Lindsay spoke of further incidents in which she and her brother had been threatened, but it was her brother who was physically threatened and robbed while out on his new bike. Nonetheless, Lindsay's brother is expected to take care of her by riding the bus home with her every day.

In speaking to Asian Muslim boys, Louise Archer (2003) argues that the boys asserted their male privilege by positioning Asian girls as lacking in agency. Girls were said by their male peers to 
be in need of protection from a "dangerous White/British society" (Archer, 2003, p.149). Archer (2003, p.150) emphasises "the portrayal of the 'dangerous' local conditions can be mobilized to justify the tightening 'protective' patriarchal relations" However, the views of these boys did not necessarily reflect those of their parents and Archer emphasises that these discourses were used to reinforce the boys' masculinity.

It remains a risk in discussing this incident that the girls' restricted access to the park might be read as a 'cultural' restriction resulting from the girls' 'oppressive' ethnic backgrounds (Basit, 1997). Dwyer (1998) describes young Muslim women's identity constructions as negotiated in direct resistance and contestation to Orientalist and racialised/gendered depictions of them. The young women's own identity constructions thus operated in awareness and resistance towards depictions of them as "not allowed to go out they are not allowed to do this, they have to cover themselves" (Quote from Robina, one of Dwyer's participants, 1998, p. 50). The young women in Dwyer's study are several years older than the girls here, who in this extract are ten years of age. Lindsay and Nilay's awareness of the ways in which they were positioned in dominant discourses were perhaps less critical/developed at this stage, though certainly they expressed criticism of "racist" practices on behalf of certain school staff.

Moreover, the girls' restrictions are not unique to them as Asian Muslim girls, and girls from all backgrounds experienced restrictions based in fears for their safety, including Spirit who lived in an expensive gated community on the outskirts of London. Similarly, Watt and Stenson (1998, p. 261) acknowledge that girls "irrespective of ethnicity or class" expressed fears about venturing outside in the evening. Women and girls who do venture out after dark may also be exposed to derogatory sexualised labelling which calls into question their moral respectability as related to their class and/or ethnic positioning (Matthews, et al., 2000). Girls living on council estates in Matthew et al's study (2000, p.74) reported being called "slags" and "tarts" because of their presence outside at a late hour.

\section{Supervised freedoms and girls as victims/vixens}

As the girls approached adolescence and entered secondary school, restrictions on their access to space continued to be emphasised and reinforced by parents, teachers and coaches. Yet 
whereas previously such restrictions had been justified in a discourse of paternal protection, they now rested more uneasily in a (begrudging) acceptance of girls' new freedoms (as 'coming of age' rites) alongside a somewhat paradoxical victims/vixens discourse. Restrictions on the girls' access to space were more readily linked to girls' 'sexual vulnerability' and exposure to 'threats' (Deakin, 2006) and yet there was an accompanying sense that any sexual attention the girls received might be linked to their developing physicalities. I suggest that it is this uneasy victims/vixens discourse which comes to complicate the earlier, more straightforward suggestion that girls are simply in need of protection.

As the girls moved in to secondary school, it was common for their physical activities to be channelled into organised (and importantly supervised) sport. At Champions Running Club where Spirit attended, the girls (ages12-17) were expected to go on a warm-up run during training which took them out of the track into a nearby park and, in the winter, onto pavements along suburban roads. The previous year, their head coach, Malcolm, had sent the girls out on the roads without any adult supervision. During a chat at the club, Spirit and her friend Suze expressed their indignation at the former practice of being sent out "on our own"! This indignation was largely due to the strong reaction the girls received from local men and boys who would shout, honk and call out to them as they ran past. After a combination of girl and parental complaints, volunteer assistant coaches began to accompany the girls on their run. One of these coaches was Mark, a well-built police officer with a bald head and joking manner. He talked a lot about protecting the girls on the first warm-up run I accompanied the group on.

We take a long route around the park, cutting through the woods at one point and then back around the grassed area. Mark explains that it is always a concern taking the girls out and he doesn't like to do it on the road because the girls get honked at constantly. He jokes that he waves back at the leering men and reasons, "they don't know these girls are only fifteen." Both Mark and Malcolm have complained about the girls dressing "inappropriately" for the runs. Overall, Mark seems very concerned about their safety and he tells me a warning story about a flasher in the park in a seeming attempt to justify his protectiveness (Fieldnotes, Champions Running Club, Summer 2007) 
Mark very much assumed the protective cop role in which girls were cast as vulnerable and in need of supervision. Certainly this sentiment was appreciated and reiterated by some of the younger girls in particular. However, Mark's opposition to the heckles the girls receive seemed to rest not so much in the sexualised, gendered and threatening nature of this harassment but in the young ages of the girls, of which he reasons the men were unaware - and therefore seemingly blameless for their comments. In separate discussions with me, Mark and the head coach Malcolm both shifted attention away from the male harassers by drawing attention to what they deemed to be "inappropriate" dress on the part of the girls. This often consisted of lycra shorts and sleeveless vests, both comfortable and conducive to running in the hot summer weather. Men and boys at the club would often run topless around the track in hot weather, and yet this was never deemed inappropriate or offensive in any way.

However, aside from being comfortable and suitable for running, it is also probable that girls' dress provided a form of sexual power for some of the older girls in particular. Certain forms of girls' dress can facilitate both agency and status, linking girls "to a particular body type, sexuality and sexual power" (Pomerantz 2008, p. 96). Older girls at the club often combined their tight running tops and short lycra shorts with carefully straightened hair, makeup and belly button rings, which suggested a particular investment in dominant constructions of heterosexual femininity. These cultural markers were combined with lean, lithe bodies honed through distance running to create the embodiment of an 'emphasised femininity' symbolised through youthfulness and (heterosexual) attractiveness. At the same time, the girls' physical capacities as high performance athletes often took onlookers and casual runners by surprise as the girls sprinted past them at impressive speeds, thus disrupting preconceptions about the bodily capacities of girls and young women.

Within the constructions of parents and coaches, girls were understood to be 'unaware' of their sexual power, and thus firmly on the side of 'innocence' in Walkerdine's (1999) framing. Walkerdine suggests that dominant discourses of girls as 'little angels' or 'seductive lolitas' position girls as either potential victims of sexual abuse or as coquettish seductresses who lure men into temptation; neither of which adequately addresses girls' complex desires and 
fantasies (Walkerdine, 1999, p. 11-12). The multifaceted configurations of such discourses suggest the ways in which girls may be 'caught up' within the enticing interpellations of sexual harassment or other heterosexualised discourses. Emma Renold's $(2005$, p.30) research also notes the duality and contradiction of sexually harassing behaviours in their ability to be both "objectifying" and "seductive." Thus harassment may not be read solely read as 'threatening' but might also constitute subjects within the bounds of attractive heteronormativity and suggest the possibilities of sexualised pleasure.

On other runs, accompanied by their male coaches and within the protection of the group, older girls would sometimes steer their path directly through a group of similarly aged boys engaging in football practice. The presence of both sets of coaches meant that no comments were exchanged as the girls successfully interrupted the training, causing most of the boys to stop and watch as the girls ran through the middle of the practice area. The presence of coaches and the security of the group seemed to provide a 'safe' space in which girls might test out their sexual power and visibility, meanwhile disrupting the masculinised space of the park, filled as it often was with the bodies of boys and men playing football.

\section{Local Harassment and Neighbourhood Threats}

The preceding description of a group of accompanied girls successfully interrupting the masculine space of the football pitch suggests a moment or set of circumstances in which the threat of violence and girls' perceived vulnerability might be interrupted or resisted. However, such instances were relatively rare and contrasted with experiences in which the girls had experienced actual threats of violence in their local areas. Lindsay's fear of violence and her parents' restrictions on her movements were clearly linked to the family's experiences of localised racism directed at them. Lindsay recounted to me an incident in which a boy at her school (also a neighbour) put a bag of dog excrement into her family's mailbox as part of what she described as a general anti-Muslim sentiment in her block of council flats. In their Year 8 interview, Lindsay and Gazza also both described incidents in which they had been threatened by an unknown male while alone in their local area. 
Lindsay: Cause there was this bloke and we were walking and he smashed his bottle and I turned around and he was like 'What? What are you looking at?' (laughs)

Sheryl: In your old neighbourhood?

Lindsay: No, this one. And then I started to leg it and he started to leg it too (laughing). I ran home but then he stopped and he was just like 'I'll get you next time.' (Gazza is laughing loudly). And the last -

Sheryl: He was running after you?!

Lindsay: Yeah, I got scared (Gazza guffaws loudly). It's not funny, she never had this before. If she gets it-

Gazza: A man swore at me the other day and called me the ' $\mathrm{B}$ ' word (both giggling). I was going through the park yeah and some man goes 'what are you looking at, you effing B?'

Lindsay: Yeah, and I never go to that park ever again. Without any adult with me, like my mum, like right next to me. I'm so scared. That park was dangerous.

(Interview, Year 8, Spring 2008)

The girls' giggles throughout this extract sit in awkward contrast with the very real and terrifying experiences these must have been for them. I was unable to restrain my shock at the prospect of being chased down the road by an unknown man, as described by Lindsay. The girls' laughing perhaps pertains to the ways in which girls' tales of sexual harassment are rarely taken 'seriously' and seems to do some work in mediating their scary experiences. Fears around girls' vulnerability that were earlier expressed by their parents and used to justify their restricted permission outside seem here to be cemented into convictions that certain spaces are dangerous and 'out of bounds.' It is important to stress that fears around girls' safety are iterated from variable positions of material social (dis)advantage and therefore neighbourhoods where girls and women are more or less likely to experience threatening incidents such as these. As noted previously, Lindsay and Gazza both lived in a deprived inner London borough 
whereas Spirit's accompanied runs took place in leafy suburban parks in statistically 'safer', areas.

In discussing Asian Muslim girls' acceptance of "restricted" freedoms, Basit (1997, p.436) suggests that the girls might be seen as mature in being able to "weigh the pros and cons of excessive freedom in the light of present day violence against women and ethnic minorities." Regardless of the statistical 'likelihood' of threatening incidents, sexual harassment and the threat of such harassment, looms large as a restraint in most women's psyches.

\section{Discussion}

The findings document the relevance of sexual harassment and restricted mobility for girls' participation in physical activities alongside an attention to the ways in which 'girls at risk' discourses constitute young, active subjects. The findings echo in many ways what previous studies have suggested in relation to the limitations placed on girls' physical mobility and access to space as well as the impact this has on girls and their conceptions of 'danger'. For example, Jo Deakin's (2006) survey of children's fears of victimisation found that girls in the same neighbourhoods feared victimisation more than boys, regardless of victimisation rates and actual threats of physical harassment posed to boys of similar ages. Stanko (1993) makes the important argument that threats and harassment against women throughout their lifetime serve as a form of 'sexual terrorism' that keeps all women hyper-alert to these threats, positioning them as personally responsible for their individual safety. This seems to have been the case in my research

These fears have often been linked to girls' "sexual vulnerability" and to boys' "physical aggression." However, such essentialist links see victimhood and violence as inherent traits of girls and boys respectively, rather than as dominant cultural constructions infused with power and holding particular implications for gendered, embodied subjects.

The findings echo the use of these discourses of "sexual vulnerability" as being mobilised to restrict girls' activities yet the analysis goes further by linking girls' physical activities and the ways in which girls came to construct 'dangerous' and 'safe' spaces. Girls' participation in sport and physical education brings their bodies into immediate and heightened encounters with 
their local contexts including neighbourhoods, school and recreational settings. Moreover, the framing of girls' spatial restrictions around an essentialized physical vulnerability seems to contrast with girls' own experiences of potential empowerment and heightened bodily competence through sports involvement. Both Gazza and Spirit trained in karate - a martial art that combines technical ability and strength as a form of self-defence. Yet neither girl seemed to be able to capitalise on the feelings of empowerment or efficacy this may have provided. Instead, their over-protection and framing as potential 'victims' of sexual assault discursively constitute the girls as 'weak' and 'defenceless'. Lastly, this intense attention to predatory strangers as sexual threats (regardless of whether or not they actually constitute such threats), nonetheless serves to minimise and/or divert attention away from the significance of the ongoing acts of sexual harassment perpetrated by known boys both in and outside of school.

It may be that the construction of 'sexual danger' as a threat posed outside the school or home, in the form of faceless sexual predators and perverts serves to shift attention away from ongoing acts of harassment and violence that occur both inside the home and from boys and men the girls may already know.

\section{Conclusion}

"the study of body-based harassment contributes to the understanding of social dynamics and the construction of gender" (then what the study says about this)

We attempted to establish this

The findings confirm this

We still need to know more about this

Throughout this paper I have considered the spatial aspects of girls' sports engagement in the mapping out of 'safe' and 'unsafe' spaces as girls struggled to enjoy their bodies in open and unrestrained ways. Girls from various social backgrounds were similarly constrained by restrictions around their spatial freedoms. These restrictions were often framed around notions of physical vulnerability and weakness associated with their gendered identities. This seemed 
to contrast with the girls' own experiences of sports participation which might open up the possibilities of capacity and self-efficacy.

I further suggested that the projection of 'sexual danger' onto faceless strangers lurking outdoors discursively shifts attention away from the ongoing sexual harassment girls experience from male peers at school and in their local communities.

An exposition of sexual harassment and physical restrictions seems to frame girls' experiences within a context of restraint and containment that leaves little space for their agency in the face of structural impositions.

An analysis of the positions taken up by girls within available discourses seems to allow more flexibility in seeing how girls are constituted as viable subjects within the available repertoires of localised gender constructs and physical spaces. As Laurie writes " the different spaces of everyday life offer different potentialities for the (re) construction of gendered identities" (Laurie, et al., 1999, p.161). This paper has explored the ways in which girls might be constituted as powerful and agentic in the process of pursuing physical activities such as running and thereby challenge gendered constructs of their bodies as weak and passive. The subject position 'female runner' is also constrained by another set of coercive discourses around health, ability, body size and shape which dictate who might run and for what purposes. The girls' experiences suggest that there might be something potentially transgressive about women moving out and taking up space in engaged, active ways. Strong reactions from male passers-by (in the form of sexualised taunts and harassment) suggest that this is so. And yet if girls move out into space (such as parks and streets) in physically engaged and active ways, this creates the opportunity for that space to be reconstituted in some way, thereby challenging both assumptions about girls' restricted physicality as well as the ways in which the female subject experiences this physicality.

Yet while a woman or girls' occupation of parks, streets and playgrounds in a physically active way might constitute her as powerful and agentic, the interpellation of her movements into an assessment of the aesthetic sexualisation of her body through harassment seems to reconstitute that body as passive, pretty, objectified. Girl's understandings of and positioning 
within such configurations are complex, contradictory and sometimes self-fulfilling. The embeddedness of sexual harassment within a context of sexist heteronormativity means that it can serve as both a form of pleasure and threat for girls. Parents and coaches were much more likely to emphasise the latter possibility, emphasising the threat of sexual danger framed in a justificatory discourse of female vulnerability and weakness.

Fears around girls' vulnerability often meant that girls did not go out running or stay after school for football training, thus limiting and constraining the physically engaged possibilities they at times experienced. Yet girls are also often resourceful and resilient, sneaking out of the house, running in groups and contesting discourses around their vulnerability and need for protection, thereby resisting dominant understandings of their embodied capacities and rightful 'place.' 


\section{References:}

Archer, L. (2003). Race, Masculinity and Schooling: Muslim Boys and Education. Maidenhead: Open University Press.

Bailey, R. (2011). Letting Children Be Children: Report of an Independent Review of the Commercialisation and Sexualisation of Childhood. Department of Education.

Bailey, R., Bloodworth, A. and McNamee, M. (2007 ). Sport, Well-Being and Gender, in I. Wellard (ed) Rethinking Gender and Youth Sport. London and New York: Routledge.

Basit, T. N. (1997). "I want more freedom, but not too much": British Muslim girls and the dynamism of family values. Gender and Education 9(4): 425-439.

Beunderman, J., Hannon, C. and Bradwell, P. (2007). Seen and Heard: Reclaiming the public realm with children and young people. London: Play England.

Brumberg, J. J. (1997). The Body Project: An Intimate History of American Girls. New York: Random House.

Cebulla, A. and Tomaszewski, W. (2009). Risky Behaviour and Social Activities. England: Department for Children, Schools and Families.

Christiansen, P. and O'Brien, M. eds (2003). Children in the city: home, neighbourhood and community, London and New York: Routledge Falmer.

Deakin, J. (2006). Dangerous People, Dangerous Places: the nature and location of young people's victimisation and fear. Children and Society 20: 376-390.

DfES (2003). Every Child Matters. Green Paper, cm.560, London: The Stationary Office.

Dwyer, C. (1998). Contested Identities: Challenging dominant representations of young British Muslim women, in T. Skelton and G. Valentine (eds) Cool Places: Geographies of youth culture. London and New York: Routledge.

Evans, B. (2006). 'I'd feel ashamed': Girls' bodies and sports participation. Gender, Place and Culture 13(5): 547-561.

Evans, J., Rich, E., Davies, B. and Allwood, R. (2008). Education, Disordered Eating and Obesity Discourse: Fat fabrication. London and New York: Routledge. 
Flintoff, A. and Scraton, S. (2001). 'Stepping Into Active Leisure? Young women's perceptions of active lifestyles and their experiences of school physical education'. Sport, Education and Society 6(1): 5-21.

Gard, M. and Wright, J. (2005). The Obesity Epidemic: Science, morality, and ideology. London: Routledge.

Guest, Andrew (2011). 'Cultures of play during middle childhood: interpretive perspectives from two distinct marginalized communities' Sport, Education and Society 18(2): 167-183.

Hall, T., Coffey, A. and Williamson, H. (1999). 'Self ,Space and Place: youth identities and citizenship'. British Journal of Sociology of Education 20(4): 501-513.

Harris, A. (2004). All about the girl: power, culture, and identity. New York: Routledge.

Heise, L. (1997). 'Violence, Sexuality and Women's Lives', in M. Di Leonardo and R. N. Lancaster (eds) The Gender Sexuality Reader. New York: Routledge.

Holman, M., Johnson, J. and Lucier, M.-K. (2013). 'Sticks and stones: the multifarious effects of body-based harassment on young girls' healthy lifestyle choices'. Sport, Education and Society 18(4): 527-549.

Johansson, K., Laflamme, L. \& Eliasson, M. (2013) 'Adolescents' Perceived Safety and Security in Public Space: A Swedish focus group study with a gender perspective.' Young 20 (1): 69-88.

Kelly, P. (2001). 'Youth at Risk: processes of individualisation and responsibilisation in the risk society'. Discourse: studies in the cultural politics of education 22(1): 23-33.

Laurendeau, J. and Adams, C. (2010). "Jumping like a girl': discursive silences, exclusionary practices and the controversy over women's ski jumping'. Sport in Society 13(3): 43-447.

Laurie, N., Dwyer, C., Holloway, S. L. and Smith, F. (1999). Geographies of New Femininities. Harlow, England: Longman.

Matthews, H., Limb, M. and Taylor, M. (2000). 'The 'street as thirdspace", in G. Valentine and S. L. Holloway (eds) Children's Geographies: playing, living, learning. London \& New York: Routledge.

McGrellis, S. (2005). 'Pure and Bitter Spaces: gender, identity and territory in Northern Irish youth transitions'. Gender and Education 17(5).

Nayak, A. and Kehily, M. J. (2008). Gender, Youth and Culture: Young masculinities and femininities. Houndsmill: Palgrave MacMillan. 
Neary, J., Egan, M., Keenan, P. J., Lawson, L. and Bond, L. (2013). 'Damned if they do, damned if they don't: negotiating the tricky context of anti-social behaviour and keeping safe in disadvantaged urban neighbourhoods'. Journal of Youth Studies 16(1): 118-134.

Nespor, J. (1997). Tangled up in School. New Jersey: Lawrence Erlbaum Associates.

Pain, R. (2003) 'Youth, age and the representation of fear' Capital \& Class 27: 151- 169.

Pike, E. C. J. (2007). Revisiting the 'Physical Activity, Sexual Health, Teenage Identity Construction Nexus. International Review for the Sociology of Sport 42(3): 309-319.

Pomerantz, S. (2008). Girls, Style and School Identities: Dressing the part. New York: Palgrave Macmillan.

Renold, E. (2002). Presumed Innocence: (Hetero)sexual, heterosexist and homophobic harassment among primary school girls and boys. Childhood 9(2): 415-434.

Renold, E. (2005). Girls, Boys and Junior Sexualities: Exploring children's gender and sexual relations in the primary school. London and New York: Routledge Falmer.

Skelton, T. (2000). "Nothing to do, nowhere to go?': teenage girls and 'public' space in the Rhondda Valleys, South Wales', in G. Valentine and S. L. Holloway (eds) Children's Geographies: playing, living, learning. London and New York: Routledge.

Stanko, E. A.( 1993). Ordinary Fear: Women, violence and personal safety, in P. B. Bart and E. G. Moran (eds) Violence Against Women: The bloody footprints. Newbury Park: Sage Publications.

UK Sport (2006). Women in Sport: The State of Play 2006. London: Women's Sports Foundation.

Unicef (2007) Child Poverty in Perspective: An overview of child well-being in rich countries, Florence: Innocenti Research Centre, Report Card 7.

Vilhjalmsson, R. and Kristjansdottir, G. (2003). Gender Differences in physical activity in older children and adolescents: the central role of organized sport. Social Science \& Medicine 56: 363-374.

Walkerdine, V. (1999). Violent Boys and Precocious Girls: regulating childhood at the end of the millennium'. Contemporary Issues in Early Childhood 1(1): 2-23.

Watt, P. and Stenson, K. ( 1998). The Street: 'It's a bit dodgy around there': Safety, danger, ethnicity and young people's use of public space, in T. Skelton and G. Valentine (eds) Cool Places: Geographies of youth culture. London \& New York: Routledge. 
Wellard, I. (2012). Body Reflexive Pleasures: exploring bodily experiences within the context of sport and physical activity. Sport, Education and Society 17(1): 21-33.

Wesely, J. K. and Gaarder, E. (2004). The Gendered "Nature" of the Urban Outdoors: Women negotiating fear of violence. Gender \& Society 18(5): 645-663.

\footnotetext{
i Tomboy identities: the construction and maintenance of active girlhoods." ESRC project number RES-00-22-1032. ${ }^{i i}$ Lindsay and Nilay were from Pakistani and Turkish backgrounds, respectively, but chose their own pseudonyms in year 5. The girls' class positioning is complex. Although they now lived in less affluent (or working class) areas, their parents had held professional qualifications and jobs in their country of origin. The girls and their parents' educational aspirations might be described as more middle class.
} 